\title{
BARALHO PEDAGÓGICO COMO FONTE DE ALFABETIZAÇÃO DE JOVENS E ADULTOS
}

Pedagogical deck as a source of literacy for young people and adults

\author{
Iracema Lídia Cabral Abreu Rodrigues ${ }^{T}$
}

\begin{abstract}
RESUMO: O presente artigo vem mostrar as dificuldades no processo de alfabetização e letramento voltada para os alunos do EJA - Educação de Jovens e Adultos, realizamos uma pesquisa para mostrar como é a realidade desse público ao qual não obtiveram oportunidades para concluir no período regular, conforme cita a sistemática educacional do nosso país. Para retratar esses desafios, realizamos uma pesquisa para termos como referencial de algum projeto aplicado, como a sua importância para esses alunos, discutem os resultados de uma pesquisa referente ao processo de ensino e aprendizado dos jovens e adultos em uma escola. Por esta razão, o objetivo geral: identificar os desafios pelas quais os jovens e adultos enfrentam no aprendizado da leitura e escrita, durante o desenvolvimento da sua vida educacional no EJA. A pesquisa foi fundamentada no trabalho de Paulo Freire, considerado um grande referencial do EJA atualmente. Os resultados revelados por esse artigo mostrando que a prática pedagógica de todo corpo escolar, contribui para que esse público consiga desenvolver-se e continuar com sua vida educacional, sendo capazes de obter senso crítico, cidadãos com seus direitos e deveres, mostrar que conseguem ler o mundo, indo muito além das expectativas, podem desenvolver habilidades e competências técnicas para conviver no meio social.
\end{abstract}

Palavras-chave: palavras-chave: Alfabetização. Educação de Jovens e Adultos. Desafios na aprendizagem.

ABSTRACT: This article shows the difficulties in the process of literacy and literacy aimed at students of EJA - Youth and Adult Education, we conducted a survey to show what the reality of this public is, which they did not get opportunities to complete in the regular period, as mentioned our country's educational system. to portray these challenges, we conducted a research for terms as a reference of some applied project, such os its importance for these students, discuss the results of a research related to the teaching and learning process of young people and adults in a school. For this reason, the general objective: to identify the challenges that young people and adults face in learning to read and write, during the development of their educational life at EJA. The research was based on the work of Paulo Freire, considered a major reference of EJA today. The results revealed by this article showing that the pedagogical practice of the whole school body, contributes to this audience to be able to develop and continue with their educational life, being able to obtain critical sense, citizens with their rights and duties, show that they can read the world, going far beyond expectations, can develop technical skills and competences to live in the social environment.

Keywords: Literacy. Youth and Adult Education. Challenges in learning.

${ }^{1}$ Licenciatura em Pedagogia pela UNIP-E-mail: Iracema.lidia@gmail.com. 


\section{INTRODUÇÃO}

A pesquisa tem como tema, "Baralho pedagógico como fonte de alfabetização de jovens e adultos", estando delimitada ao ensino das práticas da alfabetização frente aos desafios enfrentados pelos alunos da Educação de jovens e adultos. Pretendemos responder a seguinte pergunta: Por quais razões o ensino das práticas da alfabetização se torna desafiadores para os alunos da Educação de jovens e adultos?

O objetivo geral é Identificar as razões pelas quais, os jovens e os adultos enfrentam os desafios no aprendizado da leitura e da escrita, durante o desenvolvimento da sua vida educacional no EJA (Ensino de Jovens e Adultos) e os objetivos específicos são: apresentar um estudo levantando as principais razões em que leitura e escrita para os públicos de jovens e adultos se tornam desafiadores; buscar soluções capazes de amenizar os impactos que originam o não aprendizado e desenvolvimento da leitura e escrita dos jovens e adultos; apresentar um projeto político pedagógico dos processos que levam o público alvo a envolver-se a ponto de serem capazes de enfrentar os desafios, ampliando suas habilidades para êxito em sua vida educacional; apresentar mecanismos que possibilitem aos jovens e adultos compreender e usar a leitura e escrita para seu desenvolvimento educacional;

A pesquisa se justifica por apresentar a proposta educacional do programa de Alfabetização para Jovens e Adultos - EJA que foi criado para oportunizar a inclusão das pessoas adultas no aprendizado para habilitá-los para utilizar a leitura e escrita e capacitar o indivíduo a ser integrado na sociedade, não sendo ainda para os alunos o conteúdo programático a configuração de um conjunto meros códigos ininteligíveis a serem identificados a duras penas mas, sim devendo ser compreendidos em seu contexto em que vivem, possibilitando que estes alunos sejam considerados cidadãos atuantes, trazendo para suas vidas uma melhoria significativa em caráter pedagógico-social.

No passado ocorreu o Projeto Mobral do Governo Federal que foi criado em 1970 com objetivo de erradicar o analfabetismo do Brasil no lapso temporal de dez anos. O Mobral propunha a alfabetização funcional de jovens e adultos, visando "conduzir a pessoa humana a adquirir técnicas de leitura, escrita e cálculo como meio de integrá-la a sua comunidade, permitindo melhores condições de vida". O programa foi extinto em 1985 e substituído pelo Projeto Educar (TAKUNO. 200I).

A intervenção para alfabetização deste público, visto que na época a necessidade do trabalho braçal fosse mais importante para o sustento de sua família, portanto essas pessoas não puderam ser instruídas a valorizar sua alfabetização para melhoria de vida, a escola não era acessível a todos, as 
modificações da sociedade no segmento político e social puderam ter a visão das pessoas com mais idade, deveriam ter contato com a educação.

Atualmente após a inclusão dos jovens e adultos nas escolas, apresentaram desafios para ingressarem na vida escolar, por uma série de motivos ao qual não permita a conclusão dos seus estudos, barreiras essas que ultrapassam os muros das escolas, pela necessidade de trabalharem para o sustento de suas famílias, muitos desses jovens e adultos foram colocados a iniciação do trabalho de forma muito precoce.

O trabalho visa identificar e reconhecer quais dificuldades o público de jovens e adultos, inseridos neste tipo programa, enfrentam em sua vida escolar, e até mesmo quais as dificuldades a serem solucionados pela escola, e que esta pode colaborar para atender essa categoria.

É sabido por todos os educadores que a instituição educacional é a solução para o ensinoaprendizado, visando o comprometimento exercido perante a sociedade, por essas razões nós educadores devemos nos comprometer e estruturar um planejamento capaz de proporcionar aos alunos exercitar e aprender o processo da escrita e leitura, somente dar ênfase a realizar um profundo estudo para identificar os problemas e solucioná-los.

É certo que um trabalho com uma boa estrutura e muito elaborado, será capaz de obter excelentes resultados aos educadores e educandos, superando os desafios encontrados para terem a oportunidade de atuar em grupos, tornando-se efetivo em seu papel social.

Temos por hipóteses a crença de que a criação de uma metodologia que viabilize a aplicação de conteúdo disciplinar para alunos do EJA vai facilitar a aprendizagem dos alunos.

A metodologia se caracteriza por ser do tipo Documental, sendo também considerada uma forma indireta de pesquisa que utiliza fontes primárias. Esse tipo de pesquisa emprega como material fonte provenientes de informação, testamentos, leis, gravações, registros de nascimento e até fotografias.

Os documentos analisados podem ser atuais ou antigos, e empregados para fins de contextualização histórica, cultural, social e econômica de um lugar ou grupo de pessoas, em determinado lapso temporal da história. Assim sendo, é um tipo de pesquisa é bastante utilizado nas ciências sociais e humanas.

Uma das grandes vantagens da pesquisa documental é que ela permite produzir análises qualitativas sobre determinado fenômeno, todavia, também é possível produzir análises quantitativas, quando se analisam bancos de dados com informações numéricas, a exemplo. 
A pesquisa documental emprega dados primários, ou seja, os dados se encontram na sua fonte original. Significando que não ocorreu a análise aprofundada sobre as informações.

Os tipos de documentos utilizados nas pesquisas documentais variam, podem ser relatórios, tabelas, fotos, vídeos, cartas, discursos, etc. Neste caso foram empregados documento oriundos dos sites oficiais das IEA's.

A pesquisa documental é a que mais se enquadra ao escopo de solicitação do projeto pois, é muito utilizada em ciências sociais e humanas por se tratar de uma técnica que busca, através da interpretação de dados e informações, visando a compreensão de um contexto, uma realidade ou fenômeno.

Ao pesquisador, deve este estabelecer a formulação de um problema para a pesquisa, ou seja, uma pergunta que se pretende responder, e para tanto, irá fazer o uso de documentos para analisar respostas.

A pesquisa documental consiste basicamente em três etapas: a pré-análise, a organização dos documentos e a análise dos resultados.

A legislação existente para fundamentar a Educação de Jovens e Adultos se ampara em importantes diplomas legais, tais como, a Constituição Federal do Brasil, a LDB e a Resolução № 3 , De is De Junho De 2010.

Diz o artigo 205 da Constituição Federal de 1988: " A educação, direito de todos e dever do Estado e da família, será promovida e incentivada com a colaboração da sociedade, visando ao pleno desenvolvimento da pessoa, seu preparo para o exercício da cidadania e sua qualificação para o trabalho".

\section{DESENVOLVIMENTO}

Com base no estudo de caso proposto na obra Primeiras Letras, Alfabetização de Jovens e Adultos em Espaços Populares de Marlene Carvalho, com base no trabalho do então estudante de história na UFRJ que trabalhava em tempo parcial como estagiário da Ligth, devido aos baixos ganhos, ingressou no Programa da Maré.

E mesmo sendo de origem humilde se indignou com a falta de recursos que era disposto para os alunos deste programa de alfabetização de Jovens e adultos, neste ínterim refletia sobre a exclusão social que configura como a maior causa do analfabetismo no Brasil.

O ponto de inflexão no trabalho de Joaquim residia no perfil extremamente heterogêneo que apresentava um número diversificado de níveis de conhecimento e leitura. E neste momento os 
alunos iam até eles como "crianças" que demonstravam uma demanda constante de atenção do instrutor.

E um fator neste processo que chamou a atenção de Joaquim foi a determinação desmedida de seus alunos, que não poupavam esforços em trabalhar em prol de seu melhoramento como aprendizes e na aquisição de conhecimentos.

Um fator muito importante encontrado neste processo por Joaquim foi a carência de prática de leitura, chegou à conclusão de que o aprendizado não pode ser encarado de forma linear, podendo ocorrer por meio de saltos, isso é demonstrado quando o aluno falta por uma semana a exemplo, e por incrível que pareça ainda assim, apresenta algum progresso.

Dado aos diferentes níveis de conhecimento apresentado pelos alunos, Joaquim observou que alguns dos discentes sabiam "juntar" as letras, porém, conheciam muito bem o alfabeto, e que aprenderam a ler palavras simples.

Outro fator surpreendente para o alfabetizador foi o fato de alguns alunos demonstrarem, tão somente, o desejo de aprender a ler e não aprender a escrever. Onde essa ocorrência se faz comum dos cursos de EJA (SINGNORINI, KLEIMAN, 200I).

Os educadores deste seguimento obtiveram êxito tanto no campo da leitura, assim como, no campo da escrita, e segundo Joaquim:

É, no início [as frases] são bastante curtas, mas, mesmo assim estão lá[nos cartazes colados na parede]. Hoje é completamente diferente; eu dei uma frase assim, de um projeto que falava sobre educação: "Um lápis na mão, idéias na cabeça ". A aluna botou que, com o lápis na mão, a gente podia não só aprender a escrever e colocar nossas idéias, mas, também contar da nossa vida[...]. Acho que é um progresso muito grande na escrita. [A aluna] já consegue formular um texto de cinco, seis linhas.

Outro fator importante foi a constatação por parte de Joaquim que o método de Paulo Freire - que contextualiza a palavra geradora, opera em desmembrá-la em sílabas, empregar as sílabas como unidades para construção de novas palavras - se demonstra deveras eficaz.

Um outro recurso simples, porém, bastante funcional que trouxe resultados satisfatórios foi o emprego de sílabas encontradas em jornais, onde os jornais são recortados com as sílabas se colando uma folha, em que são os recortes são colados formando pequenas frases.

Joaquim também faz o que ele chama de jogo dos espelhos, onde troca de lugar com os alunos dando-lhes a palavras, assim, ocorre uma partilha mais eficaz do conhecimento. 
O emprego de fotos e gravuras age como fonte de estímulo para operacionalizar a produção de textos enriquecendo de forma significativa a prática escolar. Isto aumenta o índice de produtividade no letramento no sentido de capacitar os alunos, por si sós, a encontrarem as tarefas.

$\mathrm{Na}$ turma do alfabetizador Joaquim, seus alunos escolhiam as imagens e escreviam legendas e/ou comentários não apenas de caráter descritivo, mas, possuidores de função indicativa de demonstração de suas opiniões, pontos de vista acerca dos mais variados assuntos e seu estado de espírito.

O resultado é que se construía uma ponte de ligação entre o diálogo e imagem e o texto, entrementes, o aluno não procedia a escrita acerca da imagem em si, porém, sobre o que está lhe passava segundo seu entendimento: pensamentos, sentimentos, lembranças, críticas, ideias, anseios, desejos, necessidades, preocupações, posições políticas e religiosas, sonhos e esperanças. Nestes termos, os alunos puderam experimentar vivenciando a função e a expressão gráfica e iconográfica da escrita.

Vamos a dois exemplos deste procedimento onde os alunos escreviam o que sentiam quando lhes era demonstrado imagens do dia a dia (CARVALHO, 2009):

O cenário de pobreza no meio rural. Barracos de pau a pique, galinhas ciscando, pessoas agindo de forma indistinta. O céu azul anil. Com este quadro a aluna escreveu: BRASIL

- O Brasil é o lugar mais bonito do mundo.

- A brasileira é muito sofrida.

Como pode-se constatar em apenas duas frases e um imagem a aluna expressou as visões de contradição que pode perceber. A imagem da pobreza rural se contrapõe ao chavão: $O$ Brasil é lugar mais bonito do mundo.

E se contraponto ao outro lado, o enunciado: A brasileira é muito sofrida é coerente com a imagem dos casebres e possivelmente uma demonstração de uma imagem estilizada da própria aluna.

A torcida de futebol, homens demonstrando um fervor frenético, com os braços levantados para o alto, bandeiras tremulando e a bandeira brasileira em primeiro plano. A legenda que se segue:

Esta é a maior torcida do mundo não importa o sexo é a torcida brasileira.

Há um diálogo entre a foto e o texto: a aluna pode vislumbrou a ausência de mulheres na imagem, porém, afirma-se como membro da torcida e cidadã brasileira ao se pronunciar "não importa o sexo é a torcida brasileira". 


\section{A origem do alfabeto}

A origem do alfabeto detém um legado de diferentes culturas, que configurava num amalgama de carga cultural de diversas civilizações, contudo, os egípcios e o povos mesopotâmicos (sumérios, acadianos e babilônios) foram os precursores da escrita. O surgimento do primeiro alfabeto consonantal aconteceu cerca volta de 2000 a. C., mais de um milênio após a início da história da escrita.

Existiam duas formas de escrita que já eram conhecidas na Antiguidade, a escrita cuneiforme dos mesopotâmicos que era impressa por meio de uma pinça de bambu ou madeira, numa tábua de barro a ser cozida posteriormente e os hieróglifos dos egípcios escritos por hábeis escribas em papiros. Ambas muito bem conhecidas a séculos na região do Oriente Médio, onde se originou o primeiro alfabeto a ser usado em grande escala, o alfabeto fenício.

Antes do alfabeto fenício, se deu a constituição do primeiro alfabeto consonantal, que foi influenciado em grande parte pelos princípios alfabéticos egípcios. O primeiro alfabeto servia para representar o idioma dos trabalhadores semitas, que eram povos que já viviam nas adjacências do Antigo Egito há cerca de 5,5 mil anos.

O alfabeto dos fenícios surge como uma ponte capaz de interligar este povo com outros povos, data vênia serem grandes comerciantes e hábeis navegadores. Uma importante contribuição deste povo reside no fato deles atribuírem aos símbolos gráficos que eles simplificaram a partir dos hieróglifos egípcios os fonemas de seu idioma, algo inovador a época.

Nos dias atuais, a maior parte dos alfabetos existentes no mundo se embasaram a partir do desenvolvimento do alfabeto consonantal fenício ou foi inspirado nele. Os alfabetos têm caráter abstratos, o que facilita a sua adaptação para qualquer tipo de idioma.

$\mathrm{O}$ alfabeto mais utilizado no mundo é o alfabeto latino, quem vem da origem do alfabeto grego, que por sua vez, é considerado o primeiro alfabeto real por indicar de maneira consistente tanto letras consoantes quanto vogais.

Caixa Silábica

Trata-se de um recurso pedagógico bastante acessível desenvolvido por educadores, e que possibilitou acesso simplificado ao conteúdo proposto para os alunos.

Este recurso pode ser usado por m público muito heterogêneo, com idades entre 15 e 80 anos e detém características que são próprias dessa modalidade de ensino. O que configura no desenvolvimento de material sem características infantis para fins de vencer a resistência dos alunos 
a supostos meios pedagógicos que seriam considerados por estes como não condizente com sua faixa etária.

"A barreira inicial a ser superada era justamente o desenvolvimento de materiais próprios para a educação de jovens e adultos que não possuíssem características infantis. A proposta era de que o uso desse material pudesse auxiliar a alfabetização e letramento de estudantes, estimular o acesso às tecnologias de informação e comunicação (TICs) e contribuir para a articulação dos diversos componentes curriculares e das áreas do conhecimento" (HENRIQUE, 2019).

Existe a sugestão de fazer a caixa silábica em materiais mais acessíveis, a exemplo o Evateno, popularmente chamado de papel emborrachado, ideal para o trato de atividades pedagógicas.

"O material pedagógico acessível foi confeccionado em MDF, sendo resistente e de fácil manuseio. Ele é constituído de uma caixa sonora com i4 sílabas móveis em alto relevo, com legenda em braile Site externo, e I4 botões, que, ao serem acionados, emitem o som correspondente da sílaba " (HENRIQUE, 2019).

Umas das vantagens deste procedimento é que permite a assistência a outros seguimentos sociais. Onde o projeto foi construí-lo de forma que seu uso fosse acessível para todos os educandos e educandas, com ou sem deficiências, do EJA. Por apresentar recursos com diferentes linguagens, o material proporciona o emprego por pessoas com deficiências auditiva, visual, intelectual e detentores de baixa mobilidade física, possibilitando e ainda permite a ampliação de estratégias dos docentes fins de melhoria da aprendizagem.

A função pedagógica deste procedimento é promover o estimulo ao diálogo com a aplicação de uma dinâmica da sociedade contemporânea em moldes em que os alunos possam participar ativamente da transformação positiva tanto da sua realidade local, quanto dos desafios globais.

Pode-se ainda empregar como material auxiliar no processo pedagógico o emprego de música e de recurso audiovisuais.

"Alguns conteúdos trabalhados, como interpretação, gênero literário, música e dança circular adaptada, entre outros, foram desenvolvidos ao longo do bimestre. Para tanto, foram utilizadas diversas estratégias como leitura; roda de conversa/discussão; pesquisas digitais na sala de informática; e espaços/recursos de educação física. Finalizamos as atividades com a utilização da caixa silábica na formação de cinco palavras que resumem a avaliação dos estudantes sobre o projeto: amizade, respeito, perdão, união e graça"(HENRIQUE, 2019). 


\section{Resultados Da Utilização Da Caixa Silábica}

O trato operacional do material por jovens e adultos onde estes podem escutar o som de cada sílaba e construir palavras, frases e textos de acordo com suas hipóteses apresentadas sobre a escrita, o que resulta no estimulo à participação.

Através do aprendizado e do acesso ao conteúdo proposto para toda a turma possibilitou o trabalho pedagógico de maneira eficaz, onde será desenvolvido por meio da formação de duplas produtivas em que um dos estudantes se apresentará como o par avançado. Essa estratégia determina êxito à promoção da diversidade da sala de aula e favorece a interação e a cooperação entre os alunos.

O resultado da aplicação deste processo reside na apresentação da evidência como aspecto positivo para fins de utilização do material de forma acessível a todos, fomentando assim, um ambiente de proximidade e interesse pelo conteúdo, em que todos puderam participar ativamente e experimentar de forma satisfatória a atividade.

Não obstante, se deve ressaltamos que o material pedagógico deve ser acessível e que faz parte de um plano de aula, não descartando a mediação do professor, tem a missão de garantir êxito na produção pedagógica por meio do uso do material.

\section{PROPOSTA DE METODOLOGIA PEDAGÓGICA PARA O EJA}

Com base nos fundamentos expostos pode-se propor o projeto de uma metodologia pedagógica para o EJA que se configurará em um baralho pedagógico. Este artefato virá com gravuras impressas que remontam à origem das letras do alfabeto.

A função deste jogo além de promover a o aprendizado da leitura e da escrita, incentivará os alunos a descobrir a origem das letras do alfabeto. Isso determinará uma maior compreensão do conteúdo programático em âmbito pedagógico e histórico.

O professor deve enfatizar não só a importância do aprendizado da leitura e da escrita, mas, como o alfabeto recurso gráfico, historicamente forneceu um aporte de facilitação nas relações entre os povos. Aonde mesmo com idiomas diferentes um povo pode ser influenciado por outro pelo uso do alfabeto de outro idioma, de forma adaptada a sua realidade e contexto cultural, às suas necessidades.

Em sua origem, o princípio alfabético implica a profunda compreensão de que cada palavra da linguagem falada está formada por um conjunto de sons que se podem representar por um grupo finito de letras. Este princípio aparentemente ingênuo, quando surgiu e com o tempo, constituiu uma 
verdadeira revolução, porque permitiu que cada palavra falada de qualquer idioma fosse traduzida à escrita (WOLF, 2010).

Exemplo do método:

Ao se criar desenhos podemos atribuir valores para cada letra:

Neste exemplo vemos o que seria a escrita por meio do entendimento segundo o alfabeto fenício semita para a formação da palavra raio.

O uso de iconografia para expressar ideias ligadas às palavras.

Agora neste exemplo vemos o que seria a escrita por meio do entendimento segundo o alfabeto da língua portuguesa para a formação da palavra raio. Para a letra "R"(O grafismo de um rato); para a letra "A" (o grafismo de uma árvore); para a letra "I" (o grafismo de uma igreja); (para a letra "O" o grafismo de um olho); para enfatizar a ideia abaixo do conjunto principal de caracteres o grafismo de representando um raio

Vamos a um exemplo de como seria o baralho pedagógico voltado para a educação nos moldes do EJA:

O baralho funciona em regra onde o objetivo é que dois jogadores consigam formas o maio número de palavras, empregando as cartas. Aquele que formar o número de 5 (cinco) palavras mais rápidas do que seu adversário é o vencedor.

Vale ressaltar que neste baralho existem dois tipos de carta:

I. E outro quantitativo contendo cartas com figuras e sua respectiva letra inicial.

2. Um quantitativo de cartas com a figura de um objeto ou animal contendo o seu nome em escrita corrente do idioma português brasileiro, com a palavra separada por sílabas;

3. Número na parte superior das cartas para facilitar a sua associação.

A partida começa se tirando a sorte num cara ou coroa, ou jogo do par ou ímpar, e após o início o jogador que dá início a partida tira uma carta que se encontra virada no quantitativo de cartas com as figuras e sua respectiva identificação contida em uma palavra. Logo após vai para o outro quantitativo e retira uma carta contendo uma figura e sua respectiva inicial.

O outro jogador continuará fazendo o mesmo trabalho onde objetivará formar o mesmo número de palavras. Lembrando que vence o mais rápido.

\section{CONCLUSÃO}


Durante o presente trabalho foi observado a existência da importância do uso de um referencial embasado em ícones gráficos que serviram de ponte de ligação com o universo didático e com o universo de vivência dos alunos.

Isso fomentou o desenvolvimento de um sentimento de identificação do aluno com o conteúdo andrológico. Assim pode melhorar o seu aprendizado dado ao fato que podia reconhecer elementos do seu dia a dia na execução dos exercícios, podendo criar um certo grau de interação que possibilitava o desenvolvimento de uma linguagem própria individual embasada em impressões da sua própria realidade e do contexto social do país.

Um outro aspecto que pode ser explorado por meio do baralho andrológico é que remonta ao exercício e desenvolvimento da linguagem, de uma forma semelhante ao dos primórdios quando os antigos criaram as primeiras formas de alfabeto conectando o mundo dos objetos reais com o mundo do abstrato das ideias.

O alfabeto em si e seu emprego para dar vida a uma linguagem por si só configura em um meio de adaptação do mundo externo que viabiliza a transmissão e registro do pensamento humano.

Não obstante o baralho serve para otimizar o senso cognitivo do aluno onde não está só prezo fixamente em suas regras de forma rígida, mas, pode também interagir com outros meios de comunicação a exemplo do seu emprego em um didática empregando recortes de jornais e de revistas.

Por meio do emprego deste baralho ocorre a união de três princípios primordiais para a formação da linguagem:
a. A ideia abstrata;
b. O ícone gráfico;
c. O som dos fonemas.

O domínio destes três princípios confere ao aluno uma maior produtividade em termos didáticos podendo assim otimizar seu cabedal de conhecimento e aumentando seu nível de consciência acerca de seu papel transformador de cidadão na sociedade.

\section{REFERÊNCIAS BIBLIOGRÁFICAS}

BARCELOS, V. Educação de jovens e adultos. Petrópolis: Editora Vozes, 2012.

BRASIL. Legislação, políticas e programas para EJA. (novembro de 2020). fonte: instituto ibe: https://www.avaibe.com.br/ava/material/89/legislacao,\%2opoliticas\%20e\%2oprogramas\%2opara \%2oeja.pdf 
BRASIL. Proposta Curricular do MEC para o Io segmento do ensino fundamental da Educação de Jovens e Adultos do estado de São Paulo. (outubro de 2020). fonte: http://portal.mec.gov.br/secad/arquivos/pdf/eja/propostacurricular/primeirosegmento/proposta curricular.pdf severino, a. j. (200I). metodologia do trabalho científico. São Paulo: editora cortez.

CARVALHO, M. Primeiras letras. Rio de Janeiro: editora ática, 2009.

FREIRE, P. Pedagogia do Oprimido. Rio de Janeiro paz\&terra, 2016.

FURASTÉ, P. A. (2020). Normas técnicas para o trabalho científico. Porto Alegre: Dáctilo Plus.

HENRIQUE, Betânia Cassia, d. g. Caixa silábica. fonte: https://diversa.org.br/relatos-deexperiencia/caixa-silabica-alfabetizacao-eja-participacao Brasil, c. c. (novembro de 2020). história da alfabetização de adultos: de 1960 até os dias de hoje. fonte: https://repositorio.ucb.br:9443/jspui/handle/ro869/1548

MARQUES, P. D. História da Educação de Jovens e Adultos (EJA) no Brasil. fonte: repositório instituvional da ufpb: https://repositorio.ufpb.br/jspui/handle/r23456789/III94?locale=pt_br.

RIO DE JANEIRO. Fundamentos jurídicos da educação de jovens e adultos. set, 2020 . http://www.educacaopublica.rj.gov.br/biblioteca/portugues/oo36.html. 